Revista de Estudios Histórico-Jurídicos

[Sección historia del derecho de la Antigüedad salvo el romano]

XLII (Valparaíso, Chile, 2020)

[pp. 67-93]

\title{
ELEMENTOS ANTROPOLÓGICOS Y ÉTICOS EN EL DERECHO PENAL DE LA Biblia HeBREA
}

\author{
[Anthropological and ethical elements in the criminal law \\ of the Hebrew Bible]
}

\author{
Francisco VARO* \\ Universidad de Navarra, España
}

\section{RESUMEN}

En un acercamiento técnico a los textos jurídicos de la Biblia Hebrea se constata la presencia en ellos de elementos relevantes en la teoría del delito, como son la precisión en la definición de conductas, la toma en consideración del dolo, de la imprudencia, la existencia de circunstancias atenuantes o agravantes, o la responsabilidad por las acciones. El análisis de las distintas penas tipificadas en la Biblia Hebrea, y la justificación de ellas que se hace en los textos, ayuda a esclarecer el sentido que tiene la sanción penal. En toda la legislación bíblica se puede apreciar una prioridad de los valores humanos por encima de los bienes económicos y una conciencia de la responsabilidad individual, que llaman la atención en el contexto histórico en el que fueron compuestos esos textos. En suma, los fundamentos filosóficos y culturales subyacentes a los grandes códigos legales de la Torah irrumpieron como una notable novedad en su momento, y luego han dejado su huella en la configuración jurídica del mundo occidental.

\section{Palabras Clave}

Teoría del delito - Derecho penal - Biblia Hebrea - Código de la Alianza Código Deuteronómico - Ley de Santidad.

\section{Abstract}

A technical approach to the legal texts in the Hebrew Bible evidences the presence of relevant elements concerning the theory of crime, such as the accuracy in describing conducts, considering intentional fault, negligence, the existence of aggravating or mitigating circumstances or the responsibility for the actions. The analysis of the different sanctions identified in the Hebrew Bible and the grounds for them by the texts, helps to clarify the sense of the criminal sanction. The priority of human values above economic assets and the awareness of individual responsibility, which are noteworthy considering the historic context in which these texts were drafted, is observed all through the biblical legislation. Finally, the philosophical and cultural grounds underlying the great legal codes in the Torah emerged as a novelty at the time and have left their imprint in the legal configuration of the Western world.

\section{Key Words}

Theory of crime - Criminal law - Hebrew Bible - Covenant Code - Deuteronomic Code - Law of Holiness.

Recibido el 27 de abril de 2020 y aceptado el 1 de junio de 2020 
En la enseñanza universitaria, con frecuencia, se minimiza o se ignora la importancia de los textos religiosos en la fundamentación del derecho ${ }^{1}$. Sin embargo, al margen de las creencias que puedan tener profesores o alumnos, hay obras clásicas cuyos valores antropológicos y éticos han dejado una profunda huella en la configuración del pensamiento occidental. Entre ellas, la Biblia Hebrea ocupa un lugar relevante ya que, tanto a través de la cultura judía como del pensamiento cristiano en sus diversas confesiones, sus principios básicos proporcionan fundamentos razonables para el discernimiento de lo que es justo en la vida social y política.

En las últimas décadas se han publicado algunos estudios que se interesan por cuestiones jurídicas en la literatura bíblica ${ }^{2}$. Por lo que al derecho penal se refiere, la mayor parte de ellos se han ocupado de los delitos que son sancionados ${ }^{3}$, o las penas que se establecen para ellos, sobre todo la pena de muerte ${ }^{4}$.

Nuestro objetivo aquí no consiste en presentar lo que podría ser una aproximación a un código penal bíblico, ni un intento de sistematizarlo, sino en avanzar en la reflexión sobre lo que presuponen esas normas jurídicas acerca de la comprensión del ser humano, de la libertad, de los condicionamientos que inciden en la realización de las acciones, o del sentido de la sanción penal ${ }^{5}$.

Aquí nos ceñiremos al estudio de la Torah o Pentateuco, que es donde se concentra la más alta densidad de textos jurídicos. En los demás libros bíblicos se mencionan ocasionalmente, tanto en los textos narrativos como proféticos, e incluso sapienciales, acciones que reclaman justicia y sanciones que se aplican a los culpables, pero se trata, de ordinario, de la aplicación de normas que ya están formuladas en la Torah.

\section{LOS CORPuS JURÍdicos de la Biblia HebreA}

La Biblia Hebrea, como es bien conocido, es un conjunto de textos procedentes de distintas épocas y de muy diversos estilos literarios, entre los que destaca

${ }^{1}$ La tendencia no es nueva. En el ámbito anglosajón, desde el siglo XVIII, la rigurosa subordinación de las universidades a los intereses del Estado condujo a una progresiva positivización de la docencia e investigación. Cfr. Milbank, John, Theology and the Idea of University, en Scripta Theologica, 50/2 (2018), p. 267.

${ }^{2}$ Cfr. Westbrook, Raymond y Wells, Bruce, Everyday Law in Biblical Israel (Louisville Kentucky, Westminster John Knox Press, 2009) y Burnside, Jonathan, God, Justice, and Society (Oxford, Oxford University Press, 2011).

${ }^{3}$ Cfr. Cocco, Francesco, The Torah as a Place of Refuge. Biblical Criminal Law and the Book of Numbers (Tübingen, Mohr Siebeck, 2016); KAŠNÝ, Ji í, Criminal Law in the Hebrew Bible (en checo), en Studia theologica, 18/2 (2016), pp. 1-21; BOZHEKU, Ersi, Tracing the criminal justice: an inquiry into the roots of the modern penal principles, en Curentul Juridic, 18/2 (2015), pp. 98-101; PIKOv, Gennady, Criminal Law in the Bible (en ruso), en Schole: Ancient Philosophy and the Classical Tradition, 4/1 (2010), pp. 101-136; WeIngreen, Jacob, Concepts in Ancient Biblical Civil and Criminal Law, en The Irish Jurist, 24 (1989), pp. 113-140; L'Hour, Jean, Une législation criminelle dans le Deutéronome, en Biblica, 44 (1963), pp. 1-28.

${ }^{4}$ Cfr. Johnson, Scott L., The Bible and the Death Penalty: Implications for Criminal Justice Education, en Journal of Criminal Justice Education, 11/1 (2000), pp. 15-33.

${ }^{5}$ Sobre este último aspecto hay un estudio específico: Williams, Gary R., The Purpose of Penology in the Mosaic Law and Today, en Bibliotheca Sacra, 133 (1976), pp. 42-55. 
una gran abundancia de pasajes narrativos y legales, junto a bastantes escritos sapienciales, proféticos, poéticos, etc.

Cuando se compusieron los textos bíblicos, hace entre 2 y 3 milenios, no había en el próximo oriente un derecho penal estructurado según los parámetros actuales, ni siquiera un concepto como el que ahora se puede tener de d e r e c h o p e n a l. No existía un ordenamiento referente como una parte del ordenamiento referente a unos delitos que implican peligrosidad para las personas, los bienes o la sociedad, y las consecuencias jurídicas que se derivan de ellos como son las penas o medidas de seguridad que reclamen esos hechos. Tampoco había un derecho civil estructurado sistemáticamente como tal. Ni los confines entre derecho civil y penal eran aquellos a los que ahora estamos acostumbrados. Robos (Ex 21,27) y agresiones (Ex 21,18-19), que hoy serían contemplados en el derecho penal, en los textos bíblicos se plantean como cuestiones a dirimir entre particulares, a no ser que hayan causado lesiones permanentes o muerte. En cambio, la práctica de la brujería o adivinación (Lv 20,27), el adulterio (Dt 22,22), o el no respetar la santidad del sábado (Ex 31,13-16), que hoy son consideradas cuestiones privadas y no punibles, son consideradas en la Biblia Hebrea como graves crímenes.

De ordinario, lo que encontramos en los textos legales de la Biblia son unas normas de tipo muy variado que señalan lo que se debe hacer con un estilo más bien exhortativo, y sólo ocasionalmente se especifican razones de conveniencia para cumplirlas o se fijan penas para casos de incumplimiento. No obstante, en algunos textos narrativos y legales se pueden discernir, entremezclados con sus mandamientos o prohibiciones -tanto apodícticos como casuísticos- algunos elementos propios del derecho penal ${ }^{6}$.

Antes de pasar a estudiar más en concreto esos textos legales, recordemos que, según la investigación crítica contemporánea, en la Torah o Pentateuco se integran tres grandes códigos, a los que se añaden algunas normas dispersas en textos narrativos, de ordinario posteriores a los grandes códigos, que perfilan las prescripciones o atienden a circunstancias concretas no previstas en esas grandes colecciones. Estos códigos son los siguientes: a) El Código de la Alianza (Ex 20,22-23,19), posiblemente compuesto en tiempos del rey Ezequías de Judá (728-698 a.C.), a finales del siglo VIII a.C. ${ }^{7}$ b) El Código Deuteronómico (Dt 12,1-26,15) que constituye el núcleo central de la gran reforma llevada a cabo por el rey Josías (640-609 a.C.) unos 80 años después, en la segunda mitad del siglo VII a.C. ${ }^{8}$ c) La Ley de Santidad (Lv 17,1-26,46) compuesta en ámbitos

${ }^{6} \mathrm{Al}$ ser textos procedentes de un tiempo y un contexto cultural muy alejados de las situaciones contemporáneas no tendría sentido valorar sus aportaciones a partir de una lectura literalista de sus formulaciones. Se requiere una cuidadosa aproximación semiótica para que puedan ser relevantes en los debates actuales. Cfr. JACKSON, Bernard, On the Values of Biblical Law and their Contemporary Application, en Political Theology, 14/5 (2013), pp. 602-618.

${ }^{7}$ Cfr. Schwienhorst-Schönberger, Ludger, Das Bundesbuch (Ex 20,22-23,33). Studien zu seiner Entstehung und Theologie (Berlin, De Gruyter, 1990), pp. 285-286; OsumI, Yuichi, Die kompositionsgeschichte des Bundesbuches Exodus 20,22b-23,33 (Freiburg-Göttingen, Vandenhoeck \& Ruprecht, 1991), pp. 176-177 y 181-182.

${ }^{8}$ Se suele admitir que este código desarrolla el tratamiento que reciben varias cuestiones legales en el Código de la Alianza. Un buen ejemplo acerca de esto, en lo que se refiere a 
sacerdotales del Templo de Jerusalén reconstruido tras el exilio en Babilonia, cuando Judá no era independiente sino una provincia del imperio persa, a finales del siglo V a.C. o comienzos del siglo IV a.C.

Veamos a continuación algunas normas que permiten hacerse cargo de la creciente seriedad jurídica con la que se afrontan las cuestiones delicadas, como son aquellas que pueden llevar penas anejas.

\section{GARANTÍAS PARA ESCLARECER LA VERDAD DE LOS HECHOS: SUS PRESUPUESTOS}

\section{ANTROPOLÓGICOS}

Antes de afrontar cuestiones más específicamente relacionadas con el derecho penal en los textos de la Biblia Hebrea, puede ser oportuno reparar en algunos detalles que ponen de manifiesto el interés por conocer la verdad de los hechos con la mayor precisión posible, como presupuesto previo ineludible para su valoración penal.

De entrada, señalemos que ya en el código más antiguo, el de la Alianza, hay una mención explícita y bien significativa, de la importancia que se concede a que las causas sean juzgadas justamente: "No violarás el derecho del indigente en su pleito. Manténte alejado de causas falsas; no harás morir al inocente y al justo, porque yo no absolveré al culpable. No aceptarás soborno, porque el soborno ciega a los prudentes y pervierte las causas de los justos" (Ex 23,6-8). Desde épocas bien tempranas se hace notar uno de los grandes inconvenientes que pueden presentarse a la hora de juzgar: la existencia de sobornos o presiones por parte de los poderosos para inclinar la balanza a su favor. La advertencia es muy seria, ya que Dios mismo no absolverá al que sea culpable de violar el derecho (ya sea el que cometió la injusticia, ya el juez que le dio la razón sin deberlo).

En el código Deuteronómico, casi un siglo después, se perfilarán más detalles acerca de la justicia requerida, poniendo el acento en las garantías procesales. A la vez que se repite casi con las mismas palabras, la prevención ante el soborno ya realizada en el Código de la Alianza, se insiste en la igualdad de todos ante la ley y, para que nadie quede desatendido, se insta a que haya jueces en todas las ciudades: "Constituirás jueces y responsables para tus tribus en cada ciudad que el Señor, tu Dios, te dé. Juzgarán al pueblo con juicio justo. No darás sentencia injusta.

las cuestiones legales referentes a los extranjeros puede verse en VARO, Francisco, L'arrièreplan sociologique du champ sémantique de l'étranger dans le Pentateuque, en Revue des Sciences Philosophiques et Theologiques, 102/3 (2018), pp. 395-398. Una aproximación interesante al trasfondo sociológico de este código, con algunas referencias a cuestiones relacionadas con el derecho penal puede encontrarse en STUlman, Louis, Encroachment in Deuteronomy. An analysis of the Social World of the D Code, en Journal of Biblical Literature, 109/4 (1990), pp. 613-632.

${ }^{9}$ Para más información sobre el estado actual de las investigaciones sobre la Ley de Santidad, véase Nihan, Christophe, From Priestly Torah to Pentateuch: A Study in the Composition of the Book of Leviticus (Tübingen, Mohr Siebeck, 2007), pp. 4-11; ZENGER, Erich (ed.), Einleitung in das Alte Testament (Stuttgart, Kohlhammer, 2008), pp. 156-175. Sobre su relación con la política imperial persa, véase JONKER, Louis C., Achaemenid Understanding of Law and Justice in Darius I's Tomb Inscriptions: Are There Any Connections with Hebrew Bible Pentateuchal Conceptions?, en Scandinavian Journal of the Old Testament, 33/1 (2019), pp. 24-41. 
No harás acepción de personas. No aceptarás soborno, porque el soborno ciega los ojos de los sabios y falsea las palabras de los justos" (Dt 16,18-19) ${ }^{10}$.

En toda esta normativa subyace un extraordinario respeto por el valor de todo ser humano, por lo que, siguiendo la lógica de la justicia divina se requiere atender a lo que es justo en cada caso sin hacer acepción de personas por su origen, posición económica o situación de poder, "porque el Señor, vuestro Dios [...] no hace acepción de personas ni admite soborno; hace justicia al huérfano y a la viuda y ama al extranjero, dándole el pan y el vestido" (Dt 10,17-18). Y ese Dios, según el texto, dio órdenes a los jueces: "Oíd las causas de vuestros hermanos, y juzgad con equidad entre un hombre y su hermano, o entre él y un extranjero. No haréis en juicio acepción de personas; escucharéis tanto al pequeño como al grande; no os dejaréis intimidar por nadie, pues el juicio pertenece a Dios" (Dt 1,16-17).

En este código, el delito que se considera más grave, y que conlleva la pena capital, es la idolatría. Tratándose de pena de muerte, se insta a un cuidadoso examen del caso antes de dictar la sentencia"11. "Si en alguna de las ciudades que el Señor, tu Dios, te da para que en ella habites, oyes decir que de en medio de ti han salido hombres hijos de Belial, que seducen a los habitantes de la ciudad proponiéndoles: 'Vayamos y demos culto a otros dioses' - a los que no conocéis-, investigarás, examinarás y preguntarás cuidadosamente" (Dt 13,13-15a). Es decir, ante una acusación de esta entidad, no se debe actuar con precipitación ni a la ligera ${ }^{12}$.

Además, y no sólo en delitos que lleven aneja la pena capital, se exige como garantía que haya más de un testigo: "No será suficiente un solo testigo contra un hombre respecto de cualquier transgresión o pecado. Cualquiera que sea el delito cometido, será válida una causa avalada por el testimonio de dos o tres testigos" (Dt $19,15)^{13}$. Esto es, aunque pudiera darse el caso de que un delito grave quedara sin castigo por falta de más de un testigo, el respeto debido a todo ser humano, también al culpable, exige que no se ejecute una sentencia mientras no haya un notable grado de certeza de que es efectivamente culpable. En caso de que no haya certeza, se considera preferible dejar impune un delito antes de que pueda ser condenado un inocente ${ }^{14}$.

${ }^{10}$ Acerca de las consecuencias de esta normativa en el derecho rabínico posterior véase Flatto, David C., Constructing Justice: The Selective Use of Scripture in Formulating Early Jewish Accounts of the Courts, en Harvard Theological Review, 111/4 (2018), pp. 488-515.

${ }^{11}$ Cfr. L'Hour, Jean, cit. (n. 3), pp. 11-12.

${ }^{12}$ Cfr. Bozheкu, Ersi, cit. (n. 3), pp. 101.

${ }^{13}$ Cfr. Nelson, Richard D., Deuteronomy: A Commentary (Louisville, Westminster John Knox, 2002), p. 242; Tigay, Jeffrey H., Deuteronomy: The Traditional Hebrew Text with the New JPS Translation (Philadelphia, Jewish Publication Society, 1996), p. 183. Algunos autores han puesto en discusión la literalidad del texto bíblico tal y como figura en los manuscritos, proponiendo una reconstrucción alternativa a partir de lo que se dice en el Documento de Damasco y lo que se relata en algunos midrashim, según la cual en algunas ocasiones podría bastar un solo testigo: NAEH, Shlomo y SHEMESH, Aharon, Deuteronomy 19:15-19 in the Damascus Document and Early Midrash, en Dead Sea Discoveries, 20 (2013), pp. 179-199.

${ }^{14}$ Ese es el sentido en el que Abrahán reclama a Dios que no lleve a cabo un castigo indiscriminado, en su famoso alegato: "¿Vas a destruir al justo con el malvado? Quizá haya cincuenta justos dentro de la ciudad; ¿la vas a destruir?, ¿no la perdonarás en atención a los cincuenta justos 
En cualquier caso, también habrá de ser valorado críticamente el testimonio de los testigos que se presenten hasta cerciorarse de su verdad, y advirtiendo del delito que cometen los que acusen o testimonien en falso de las penas a las que se exponen: "Los jueces investigarán cuidadosamente. Si el testigo resulta ser falso, y ha calumniado a su hermano, le haréis a él lo que pretendia hacer a su hermano. Asi quitarás la maldad de en medio de ti. Los demás, al oírlo, temerán y no volverán a cometer una maldad semejante. Tus ojos no se compadecerán de él: Vida por vida; ojo por ojo; diente por diente; mano por mano; pie por pie" (Dt 19,18-21). Estas disposiciones acerca del que testifica con falsedad tienen como objeto, sobre todo, proporcionar un elemento disuasorio para el falso testimonio ${ }^{15}$. Se trata en una vertiente poco conocida y bien notable de la ley del talión, orientada a desincentivar acusaciones calumniosas.

La pena sólo se puede ejecutar tras haberse asegurado de los hechos: "Si se encontrara en medio de ti, en alguna de las ciudades que el Señor, tu Dios, te va a dar, un hombre o una mujer que haga el mal a los ojos del Señor, tu Dios, transgrediendo su alianza, y que vaya a dar culto a dioses extraños y se prosterne ante ellos -ante el sol, la luna o cualquiera de los seres de los cielos-, cosa que yo no he mandado, y te es denunciado, una vez que hayas oido y hecho una buena indagación, si es verdadero y cierto que se ha cometido tal abominación en Israel, sacarás a ese hombre o a esa mujer-que ha hecho tal maldad-a las puertas de tu ciudad y lapidarás a tal hombre o a tal mujer hasta que mueran"(Dt 17,2-5). Se reafirma de nuevo, pues, la necesidad de asegurarse, tras una buena indagación, de que ciertamente se han cometido unos hechos que están explícitamente señalados en la ley como merecedores de esa pena.

La cuestión es de tal importancia, que si no hay medios para resolverla adecuadamente a nivel local en los tribunales ordinarios (Dt 16,18-19), se exhorta a recurrir a un tribunal que tenga las debidas garantías: "Si en tus ciudades te resulta demasiado dificil juzgar alguna causa referente a delitos de sangre, litigio de derechos, lesiones y querellas, levántate y sube al lugar que haya elegido el Señor, tu Dios" (Dt 17,8), es decir, a la capital Jerusalén donde están los más altos dignatarios del templo y del reino ${ }^{16}$.

En el tercer gran código, la Ley de Santidad, más de dos siglos más tarde, esa normativa está ya bien asentada, pero no se considera superfluo insistir acerca de la importancia del juicio justo: "No juzgarás injustamente, ni por favorecer al pobre ni

que haya dentro de ella? Lejos de ti hacer tal cosa; matar al justo con el malvado, y equiparar al justo y al malvado; lejos de ti. ¿Es que el juez de toda la tierra no va a hacer justicia?" (Gn 18,23-25).

${ }^{15}$ Cfr. L’Hour, Jean, cit. (n. 3), pp. 18-19. La ley de Babilonia también prescribía un trato similar tanto para el falso testigo como para el falso acusador. Cfr. FrYMER-KensKY, Tikva, Tit for tat: The Principle of Equal Retribution in Near Eastern and Biblical Law, en Biblical Archeologist, 43 (1980), p. 231.

${ }^{16}$ A partir de la traducción griega del Pentateuco comenzó a difundirse una interpretación de este texto que más allá de lo que el texto mismo dice, apunta a la constitución de un "tribunal supremo". Cfr. PEARCE, Sarah, Speaking with the voice of God: the high court according to Greek Deuteronomy 17:8-13, en HeMPEL, Charlotte y LIEU, Judith M. (eds.), Biblical traditions in transmission: essays in honour of Michael A. Knibb (Leiden -Boston, Brill, 2006), pp. 237-247. Véase también FlatTo, David C., cit. (n. 10), pp. 488-515. 
por honrar al poderoso. Juzgarás con justicia a tu prójimo"(Lv 19,15). En ese mismo pasaje, un poco más adelante, es bien significativo el contexto en que se habla de hacer justicia: "No cometeréis injusticia en el juicio, ni en la medida, en el peso o en el volumen. Usaréis balanzas, pesos, efah e hin exactos"(Lv 19,35-36a). Se entiende que hacer justicia en un juicio exige aquilatar los detalles, definir las conductas, con una precisión análoga a la que cabe exigir en un peso o medida exacta.

III. LiberTAD y RESPONSABILIDAD EN LA REALIZACión DE LAS ACCIONES. POSIBLES CONDICIONAMIENTOS

En la base de todas las normas penales que se pueden encontrar en los códigos legales bíblicos subyace la idea de que el ser humano es libre y responsable de su actuar, aunque en las acciones concretas que ha llevado a cabo han podido influir algunos condicionamientos que han incido en su actuación y que es necesario ponderar en justicia.

Ya hemos observado la importancia que se da en los textos bíblicos a la necesidad de buscar la verdad de los hechos, antes de imponer pena alguna. No pocas normas descienden a detalles concretos que ayudan a valorar con rigor a lo sucedido.

\section{Actos humanos: acción u omisión}

Toda lesión de un bien jurídico deriva de una acción o de una omisión. No es de extrañar, por tanto, que en los textos bíblicos se preste atención tanto a acciones deliberadas como a omisiones que lesionan algún bien que es necesario salvaguardar.

Cabe observar, en efecto, que los códigos bíblicos especifican como delitos algunas acciones concretas (matar, robar, cometer adulterio, dar culto a los ídolos, blasfemar el nombre de Dios, etc.), pero también señalan explícitamente que constituye delito omitir algo debido. La casuística ligada a las omisiones es particularmente interesante, y nos vamos a detener algo más en ella.

Un primer ejemplo lo encontramos en el libro de Levítico a propósito del caso en que alguien que ha sido llamado como testigo calla algo que ayudaría a esclarecer el caso: "Si alguien peca porque se le toma juramento para que testifique de algo que ha visto o que sabe y no lo declara, incurre en delito" (Lv 5,1).

Así mismo incurre en delito el que ha descuidado una vigilancia responsable cuando le era debida. Tal es un caso previsto en el Código de la Alianza, el más antiguo código legal: "Si uno entrega en depósito a su prójimo un asno o un bueyo una oveja o cualquier otro animal, y mueren, se dañan o son robados, sin que nadie lo vea, se interpondrá entre ambos el juramento por el Señor de que aquél no ha puesto sus manos en la propiedad de su prójimo; el propietario aceptará el juramento y el depositario no tendrá que pagar. Pero si se lo robaron en su presencia, tendrá que pagar al dueño" (Ex 22,9-11). Esto es, si el daño ha sido producido sin que el depositario pudiera hacer algo por impedirlo, no tiene culpa, pero si estaba presente cuando alguien se lleva el animal, debería haber intervenido para impedirlo. La omisión de su deber le obliga a resarcir el precio de lo robado. 
Cuando la omisión es significativa puede cambiar radicalmente la pena que se imponga. En el Código Deuteronómico se plantea un caso llamativo: "Si una joven virgen está desposada con un hombre, y otro la encuentra en la ciudad y yace con ella, sacaréis a ambos a la puerta de esa ciudad y lapidaréis a ambos hasta que mueran: a la joven porque no gritó estando en la ciudad, y al hombre porque violó a la desposada de su prójimo. Asi quitarás el mal de en medio de ti. Pero si el hombre encuentra en el campo a la joven desposada y sujetándola por la fuerza yace con ella, morirá sólo el hombre que yació con ella. No harás nada a la joven, pues no hay en ella culpa de muerte, porque es como si se alza un hombre contra su prójimo y lo mata: asi es este caso; porque al encontrarse en el campo la joven desposada, aunque gritara, no habría nadie que pudiera librarla" (Dt 22,22-27) ${ }^{17}$. El legislador entiende que cuando una mujer está siendo violada, y no teniendo relaciones consentidas, tiene obligación de reclamar auxilio. Si hay gente que pueda oírla, como sucede en la ciudad, la omisión de su petición de auxilio se la considera manifestación de consentimiento, y eso la hace rea de muerte. En cambio, cuando la mujer ha sido asaltada y forzada en contra de su voluntad, es inocente y no merece pena alguna ${ }^{18}$.

Recordemos que la pena de muerte en caso de adulterio no deriva del hecho de tener relaciones sexuales sino de la infidelidad al marido que implica esa acción si la mujer está desposada o casada. Un cambio en esa circunstancia haría que la misma acción natural tenga una consideración jurídica y unas consecuencias distintas: "Si un hombre encuentra a una joven virgen, que no está desposada, y la sujeta y yace con ella, y son sorprendidos, el hombre que ha yacido con ella entregará al padre de la muchacha cincuenta piezas de plata. Quedará como esposa suya, puesto que la humilló: no podrá repudiarla en toda su vida" (Dt 22,28-29) ${ }^{19}$. La simple violación, pues, no implica para el agresor la pena de muerte, sino que se resuelve con el pago de una indemnización al padre de la víctima y la obligación de tomarla como esposa y no repudiarla nunca ${ }^{20}$. Un ejemplo más de la importancia que tiene esclarecer las circunstancias y definir las conductas con toda precisión, antes de dictar una sentencia penal.

Ya hemos señalado antes que puede ser punible tanto una acción como la omisión de una acción debida en algunas circunstancias. En este ámbito de responsabilidades, también se toman en consideración las negligencias y omisiones imprudentes de las que se puede derivar un daño para una persona o una propiedad, que sería necesario haber previsto.

En el Código de la Alianza, el más antiguo, ya se mencionan diversas casuís-

${ }^{17}$ Cfr. Berlin, Adele, Sex and the Single Girl in Deuteronomy 22, en Fox, Nili Sacher, Glatt-Gilad, David A. y Williams, Michael J. (eds.), Mishneh Todah: Studies in Deuteronomy and its cultural environment in honor of Jeffrey H. Tigay (Winona Lake Ind., Eisenbrauns, 2009), pp. 106-108.

${ }^{18}$ Cfr. Weingreen, Jacob, cit. (n. 3), pp. 127-128.

${ }^{19}$ Cfr. Berlin, Adele, cit. (n. 17), pp. 103-106.

${ }^{20}$ Algo análogo se establece en otras legislaciones del próximo oriente antiguo. Cfr. WAGNER, Angela B., Considerations on the Politico-Juridical Proceedings of Genesis 34, en Journal for the Study of the Old Testament, 38/2 (2013), pp. 152-153. 
ticas, propias de la vida campesina, que se pueden presentar y que es necesario prever. Veamos algunos ejemplos.

En el caso de que una persona muera en el campo por la acción de un animal, se entiende como un accidente del que, en principio, nadie es responsable: "Cuando un buey cornee a un hombre o a una mujer, y le causa la muerte, será apedreado; no se comerá su carne, pero el dueño quedará exculpado” (Ex 21,28). Pero si era previsible que sucediera, y su amo no estuvo atento, hubo negligencia y el propietario se hace responsable de lo ocurrido: "Pero si el buey ya corneaba antes y su dueño, aun sabiéndolo no lo tenía vigilado, en caso de que el buey mate a un hombre o a una mujer, el buey será apedreado y también su dueño será reo de muerte" (Ex 21,29) ${ }^{21}$. Aunque, en este caso, se podrá evitar la ejecución mediante el pago de una compensación económica a la familia, o si se trata de un esclavo, a su dueño (Ex 21,30-32) ${ }^{22}$.

También se han de prever los posibles daños a animales o bienes de otros: "Cuando uno abra un pozo o excave una cisterna y no lo tape, y cae alli un buey o un asno, el propietario de la cisterna pagará con dinero: resarcirá al dueño de los animales, y la res muerta será para él. Cuando un buey cornee a otro buey y le cause la muerte, venderán el buey vivo y se repartirán el dinero; y también se repartirán la res muerta. Pero si era notorio que el buey corneaba antes y su dueño no lo tenía vigilado, éste deberá pagar buey por buey y el animal muerto será para él" (Ex 21,33-36)23.

Los incidentes ligados a tareas agrícolas o ganaderas también han de ser vigilados para no dañar la propiedad ajena: "Cuando uno destroce un campo o una viña, dejando a su ganado pastar en campo ajeno, pagará con lo mejor de su ganado y lo mejor de su viña. Cuando se declare un incendio y se propague por los espinos devorando haces, mieses o un campo, el que provocó el incendio deberá indemnizar" $\left(\right.$ Ex 22,4-5) ${ }^{24}$.

En el Código Deuteronómico el cuidado por evitar accidentes mortales, llega a precisiones concretas para la construcción: "Si edificas una casa nueva, hazle un pretil al terrado, para que si alguien se cayera de él no te hagas responsable de sangre por razón de tu casa" (Dt 22,8) 25 .

\section{Elementos que influyen en la voluntariedad de la acción}

Elemento esencial del obrar humano es la voluntariedad de la acción. Cuando se ha causado un daño, es importante a la hora de hacer justicia, y también en el momento de considerar si es necesaria una sanción suplementaria a la reparación del daño cometido, valorar hasta qué punto ha sido voluntariamente. Por ejemplo, no es lo mismo causar un mal accidentalmente o por alguna circunstancia inevitable que hacerlo dolosamente.

${ }^{21}$ Cfr. WeingreEn, Jacob, cit. (n. 3), pp. 125-127.

${ }^{22}$ Cfr. SeEbass, Horst, Zum Sklavenrecht in Ex 21,28-32 und der Diskrepanz zwischen Ersatzrecht und Todesrecht, en Zeitschrift für altorientalische und biblische Rechtsgeschichte, 5 (1999), pp. 179-185.

${ }^{23}$ Cfr. Weingreen, Jacob, cit. (n. 3), pp. 133.

${ }^{24}$ Cfr. ibíd., p. 134.

${ }^{25}$ Cfr. ibíd., pp. 133-134. 
En la Ley de Santidad, el código legal más tardío de los incluidos en el Pentateuco, se establece que cuando hay voluntariedad de delinquir en negocios pecuniarios, además de la restitución se ha de pagar un suplemento por el daño producido: "Si alguien peca y ofende al Señor, engañando a un compatriota suyo en lo referente a un depósito, o en algo confiado a su custodia, o bien porque le robó, o le quitó algo a la fuerza [...] lo restituirá integramente y añadirá un quinto de su valor, entregándolo a su propietario el día del sacrificio por el delito. Yofrecerá al sacerdote como sacrificio por el pecado para el Señor un macho cabrio del rebaño, sin defecto, según la tasación hecha, como sacrificio por el delito" $(\operatorname{Lv} 5,21.24 \mathrm{~b}-25)^{26}$.

Obsérvese, de paso, en esta norma algo que es bastante característico del derecho bíblico, especialmente en la Ley de Santidad, y es la fuerte imbricación entre los aspectos jurídicos y religiosos, de modo que en este caso la restitución y reparación del daño tiene lugar en una ceremonia de tipo religioso, en concreto en la ofrenda de un sacrificio en el Santuario.

Si la existencia o no de voluntariedad es algo relevante en todas las causas, lo es máximamente en aquellas que llevarían aneja una condena a muerte. Por eso en las normas legales de la Biblia Hebrea acerca del homicidio se concede mucha importancia a la toma en consideración de si la acción ha sido premeditada y voluntaria, o si se ha producido la muerte de alguien sin buscarla directa o indirectamente ${ }^{27}$. Sólo en el primer caso el homicida será condenado a muerte. En el segundo, se establecen normas legales para proteger su vida en un contexto social en el que se daba por supuesta la venganza de sangre por parte de los parientes del fallecido ${ }^{28}$.

La legislación es bastante detallada desde las normas más antiguas. En el Código de la Alianza ya se dice: "El que hiera a un hombre causándole la muerte deberá morir. Si no estaba al acecho, sino que Dios permitió que cayera a manos de él, yo te mostraré un lugar donde pueda refugiarse; pero si por odio uno llega a matar a su prójimo con alevosía, hasta de mi altar lo arrancarás para darle muerte" (Ex 21,12-14). Es decir, si en una riña espontánea, o en alguna otra circunstancia no buscada intencionalmente, uno ha dado muerte a otro, tendrá previsto un lugar de refugio siempre que no haya causado la muerte por odio o premeditadamente o con alevosía. En cambio, cuando lo ha matado intencionalmente la pena ha de ejecutarse sin que sea posible buscar un refugio ni ofrecer una compensación pecuniaria alternativa ${ }^{29}$.

Casi un siglo después, en el Código Deuteronómico, se concreta alguna de las circunstancias en las que puede producirse una muerte accidental y en las que el

${ }^{26}$ Cfr. ibíd., pp. 131-132.

${ }^{27}$ Cfr. BozHeKU, Ersi, cit. (n. 3), pp. 99-100. La distinción entre la muerte producida de modo involuntario y la intencional también está presente en la legislación hitita; $\mathrm{fr}$. GOETZE, Albrecht (trad.), The Hittite Laws, $\$ \$ 3.4$, en PriTCHARD, James B., Ancient Near Eastern Texts Relating to the Old Testament (Princeton, Princeton University Press, 1950), p. 139.

${ }^{28}$ Cfr. Weingreen, Jacob, cit. (n. 3), pp. 121-122.

${ }^{29}$ Cfr. Burnside, Jonathan, cit. (n. 2), pp. 255-265; NARdoni, Enrique, Rise Up, O Judge: A Study of Justice in the Biblical World (Peabody Massachusetts, Hendrickson Publishers, 2004), pp. 74-75. 
causante de la muerte tiene derecho a refugiarse: "si uno va con su prójimo al bosque a cortar leña y, al manejar con fuerza el hacha para cortar un árbol, se desprende el hierro del mango y alcanza a su prójimo y muere, podrá refugiarse en una de esas ciudades y salvar la vida" (Dt 19,5) (10. $^{30}$.

Cuando en una legislación sacerdotal tardía, se señalen en el libro de los Números cuáles serán las ciudades específicas en las que se ejercerá ese derecho de refugio, se especifica con una casuística concreta en qué casos hubo dolo y por tanto el agresor es reo de muerte: "Si uno golpea a otro con un objeto de hierro y el otro muere, es un homicida; el homicida morirá sin remedio. Si lo golpeó teniendo en la mano una piedra que pueda causar la muerte y murió, es un homicida; el homicida morirá sin remedio. Si lo golpeó teniendo en la mano un objeto de madera que pueda causar la muerte y murió, es un homicida; el homicida morirá sin remedio. [...] Si uno por odio empuja a otro o le arroja algo premeditadamente y el otro muere, o si por enemistad le golpea con su mano y muere, el que golpeó morirá sin remedio; es un homicida. El vengador de la sangre matará al homicida cuando se tope con él" (Nm 35,16-18.20-21) $)^{31}$.

Pero a continuación también se señala en qué casos no hubo dolo ${ }^{32}$ : "si de improviso, sin enemistad, uno empuja a otro, o le arroja cualquier objeto sin premeditación, o cualquier piedra que pueda causar la muerte, sin mirar, y le cae encima y

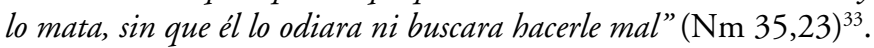

En algunas ocasiones también pueden infringirse normas por acciones $\mathrm{u}$ omisiones realizadas sin una voluntariedad deliberada, sino por inadvertencia o por precipitación. De ordinario, se señala explícitamente que esa inadvertencia no excusa de la culpabilidad, pero si no ha tenido más graves consecuencias en la vida o los bienes de otros, al culpable, más que una pena en sentido estricto, se le prescriben algunas acciones dirigidas a reparar el desorden establecido: "Si alguien toca algo impuro, como el cadáver de una bestia impura, el de un animal impuro o de reptil impuro, aun sin advertencia, y queda impuro, se hace culpable. O cuando toca impureza de hombre, cualquier impureza que contamine, aun sin advertencia, cuando cae en la cuenta, se hace culpable. O cuando alguien jura hacer el mal o hacer el bien, empleando a la ligera sus labios, esto es, en cualquier caso que uno haya hecho a la ligera un juramento, aun sin advertencia, cuando cae en la cuenta, se hace

${ }^{30}$ Para más detalles, véase STACKERT, Jeffrey, Why does Deuteronomy legislate cities of refuge?: asylum in the covenant collection (Exodus 21:12-14) and Deuteronomy (19:1-13), en Journal of Biblical Literature, 125/1 (2006), pp. 23-49.

${ }^{31} \mathrm{El}$ texto de Números perfila e introduce algunas precisiones y nuevos detalles con respecto a la legislación anterior. Cfr. MatTison, Kevin, Contrasting Conceptions of Asylum in Deuteronomy 19 and Numbers 35, en Vetus Testamentum, 68/2 (2018), pp. 232-251. Véase también HaDAD, Eliezer, 'Unintentionally' (Numbers 35:11) and 'Unwittingly' (Deuteronomy 19:4): Two Aspects of the Cities of Refuge, en AJS Review, 41/1 (2017), pp. 155-173.

${ }^{32}$ Sobre la importancia que tiene en la ley bíblica sobre el homicidio la existencia o no de premeditación, véase JACKSON, Bernard, The Problem of Exod. xxi.22-25 (Ius Talionis), en Vetus Testamentum, 23 (1973), pp. 288-90.

${ }^{33}$ Acerca de las distintas casuísticas, y en qué circunstancias puede dejar la ciudad de refugio, cfr. WhiteKeTtLe, Richard, Life's Labors Lost: Priestly Death and Returning Home From a City of Refuge in Ancient Israel, en Harvard Theological Review, 111/3 (2018), pp. 333-356. 
culpable de ellos. Todo el que se haya hecho culpable de alguna de esas formas tendrá que confesarse culpable de aquello en lo que ha pecado. Llevará al Señor como sacrificio de reparación por el pecado que cometió, una hembra del rebaño, oveja o cabra, en expiación. Y el sacerdote hará por él el sacrificio expiatorio por su pecado" (Lv 5,2-6).

La toma en consideración de la posible inadvertencia es decisiva para la sentencia. Así, en el Levítico se dice que "si por inadvertencia alguien come una cosa santa, restituirá al sacerdote la cosa santa y añadirá un quinto" $(\operatorname{Lv} 22,14)^{34}$. Todo se resuelve con la restitución de una pieza de comida análoga a la consumida y una multa. Sin embargo, si no hubiera inadvertencia, la sentencia podría ser de muerte: "Guardarán mis disposiciones para que no incurran en pecado y mueran por haberlas profanado. Yo soy el Señor que los santifico. Ningún profano comerá las cosas santas. Ni el huésped de un sacerdote ni el jornalero pueden comer cosas santas" (Lv 22,9-10). Las últimas precisiones del texto que acabamos de mencionar ponen de manifiesto que, a pesar de que la inadvertencia o la precipitación no eximen del delito, sí que requieren expiación, y esto implica llevar a cabo una acción religiosa para reparar el desorden ${ }^{35}$ : "Si alguien peca haciendo algo de lo que prohíben los mandatos del Señor, aunque no lo sepa, se hace culpable e incurrirá con su delito. Llevará al sacerdote como sacrificio por el delito un macho cabrio del rebaño, sin defecto, según la tasación hecha. El sacerdote hará la expiación por él, por lo que hizo sin advertencia, sin saberlo, y le quedará perdonado" (Lv 5,17-18).

\section{Circunstancias atenuantes o agravantes}

La precisión en la delimitación de las acciones y los sujetos a los que es imputable su autoría, así como si ha habido una causación directa o indirecta ${ }^{36}$, son elementos necesarios para establecer y ajustar la pena que corresponda a una acción determinada.

En el Código de la Alianza se puede encontrar una casuística que invita a ponderar todos y cada uno de los detalles que sea justo tener en cuenta ya que pueden constituir circunstancias atenuantes o agravantes. Allí se dice que "cuando dos hombres riñan, y uno hiere a su prójimo con una piedra o con el puño y no muere pero tiene que guardar cama: si se levanta y puede caminar por la calle apoyado en su cayado, el que le hirió quedará exculpado; sólo tendrá que pagar lo que haya perdido por la enfermedad y los gastos de la curación” (Ex 21,18-19). Si en el fragor de la pelea alguien inflige heridas que podrían haber causado la muerte, pero de las

${ }^{34}$ En diversos lugares de la Torah se considera la i n a d v e r t e n c i a como una transgresión involuntaria de un precepto que prohíbe hacer ciertas cosas. Cfr. DeIANA, Giovanni, Levitico (Milano, Paoline, 2005), pp. 70-71.

${ }^{35}$ A diferencia de otras legislaciones cultuales en el próximo oriente, la ley bíblica autoriza la redención de ciertas faltas, como las debidas a inadvertencia, sobre las cosas sagradas. $C f r$. Milgrom, Jacob, Leviticus 1-16. The Anchor Bible, (New York, Doubleday, 1991), pp. 324-325.

${ }^{36}$ Cfr. Daube, David, Direct and Indirect Causation in Biblical Law, en Vetus Testamentum, 11 (1961), pp. 246-269. 
que el agredido se recupera, será necesario pagar por los daños causados ${ }^{37}$, pero no se le culpará de homicidio ${ }^{38}$.

Estas precisiones son especialmente chocantes para nuestra mentalidad cuando de esclavos se trata: "Cuando uno golpee con un bastón a su esclavo o a su esclava, y mueren a manos del dueño, será reo de venganza; pero si sobrevive un día o dos, no será reo, puesto que es parte de su hacienda" (Ex 21,20-21). En este caso es una llamada de atención a que los amos no se excedan en el castigo a sus esclavos, ya que si mueren a sus manos por los golpes recibidos el agresor será reo de muerte. No así si el fallecimiento no es inmediato, pues en ese caso se considera que es simple consecuencia de una paliza a algo que es propiedad suya. En el caso de lesiones físicas permanentes sufridas por los esclavos ${ }^{39}$, se establece la obligación de dejarlo en libertad como modo de compensación por el daño infligido (Ex 21,26-27).

También han de evaluarse las consecuencias penales de los golpes que puedan provocar la anticipación del parto de una mujer, tomando en consideración las consecuencias que esto haya tenido: "Cuando algún hombre, en el fragor de una riña, golpee a una mujer embarazada provocándole el parto ${ }^{40}$, pero sin causar más daño, el culpable será multado según lo que imponga el marido de la mujer y decidan los magistrados. Pero si se sigue algún daño, pagarás vida por vida” (Ex 21,22-23).

Resulta muy ilustrativa acerca de la importancia de algunas circunstancias concomitantes a la acción que se juzga, que pueden ser atenuantes o agravantes, una norma del Código de la Alianza, presentada con el estilo casuístico tan característico de esta antigua colección legal: "Si un ladrón es sorprendido asaltando una propiedad, es herido y muere, no habrá venganza de sangre; pero si ya luce el sol, habrá venganza de sangre" (Ex 22,1-2). El que la acción sea cometida de día o de noche, cambia ${ }^{41}$. En medio de la confusión de la noche, el que defendiendo sus bienes da muerte al asaltante no puede ser inculpado. Pero a la luz del día, provocar la muerte de quien está robando sería una medida desproporcionada que puede ser castigada.

${ }^{37}$ Según otra posible traducción del texto hebreo, que aquí resulta especialmente oscuro, a la luz de los paralelos hititas, podría ser: "tendrá que prestarle ayuda en su lugar". Cfr. FENSHAM, F. Charles, Exodus 21:18-19 in the light of Hittite law 10, en Vetus Testamentum, 10/3 (1960), pp. 333-335.

${ }^{38}$ Cfr. Weingreen, Jacob, cit. (n. 3), pp. 122-123.

${ }^{39}$ Probablemente se trata de israelitas empobrecidos que no han tenido más remedio que venderse a la esclavitud para pagar así sus propias deudas. Cfr. JACKSON, Bernard, Wisdom \& Laws: A Study of the Mishpatim of Exodus 21:1-22:16, (Oxford, Oxford University Press, 2006), p. 249.

${ }^{40} \mathrm{El}$ texto alude a un parto prematuro pero donde el niño nace vivo. Cfr. MaKUjINA, John, The Semantics of in Exodus 21:22: Reassessing the Variables that Determine Meaning, en Bulletin for Biblical Research, 23/3 (2013), pp. 305-321. Si le hubiera provocado un aborto espontáneo la situación sería distinta.

${ }^{41}$ Cfr. Schoneveld, Jacobus, Le sang du cambrioleur: Exode 22:1,2, en BöHL, Franz Marius Theodor y BEEK, Martinus Adrianus (eds.) Symbolae Biblicae et Mesopotamicae: Francisco Mario Theodoro de Liagre Böhl dedicatae (Leiden, Brill, 1973), pp. 335-340. 


\section{LA SANCIÓN PENAL}

No podemos prescindir, en este acercamiento a algunos rasgos del derecho penal en la Biblia Hebrea, de pasar revista a las penas que podemos encontrar tipificadas en sus textos legales.

El hecho de que determinadas conductas estén sancionadas explícitamente con una pena implica un reconocimiento implícito de la libertad humana y consiguientemente de la responsabilidad con la que cada uno ha de asumir su propia conducta. Cuando haya circunstancias que exijan ser tomadas en consideración, como la inadvertencia o la falta de premeditación, se tendrá en cuenta, como hemos visto, pero si hay acciones por las que se puede castigar a alguien es porque se reconoce que hay personas que actúan en contra de la ley voluntariamente.

Entre todas las penas previstas, la más fuerte y reservada para cuestiones a las que se concede particular relevancia, es la pena de muerte ${ }^{42}$. Pero también se mencionan otros daños corporales, como mutilación o, sobre todo, azotes, y para infracciones menos graves, compensaciones o penas económicas.

En toda la legislación bíblica nunca se menciona la pena de cárcel o privación de libertad. Sí que se habla en algunas ocasiones de la cárcel como un lugar donde se encierran personas que se consideran peligrosas o que podrían escaparse si estuviesen libres, pero no se contempla el caso de encerrar a alguien durante un cierto tiempo como pena por un delito cometido ${ }^{43}$.

\section{Pena de muerte}

Las infracciones que se consideran más graves están penadas con la pena capital. Ocupan un lugar importante entre éstas las que tienen que ver con faltar el debido respeto a las cosas santas (también a los tiempos y lugares santos), ultrajar el nombre de Dios o dar culto a los ídolos.

En el Código de la Alianza, el más antiguo, ya se establece la prohibición de trabajar en sábado como modo de respetar la santidad del día: "Durante seis días trabajaréis, pero el día séptimo será para vosotros sagrado, día de descanso completo en honor del Señor. Todo el que haga algún trabajo en él morirá" (Ex 35,1-2).

En el Código Deuteronómico, como ya se dijo, se considera especialmente grave la idolatría, por lo que se la castiga con la pena de muerte (Dt 17,3-5). También es reo de la pena capital quien secuestre a otro hombre, aunque no le cause la muerte: "Si se descubre a un hombre que ha raptado a uno de sus hermanos entre los hijos de Israel, y lo retiene como esclavo o lo ha vendido, ese ladrón debe morir: asi quitarás el mal de en medio de ti" (Dt 24,7) ${ }^{44}$.

En el código más tardío, la Ley de Santidad, donde las cuestiones relacionadas con el respeto al orden establecido por Dios, tanto en el culto como en la vida ordinaria, tienen mucha importancia, se impone con fuertes medidas la obligación de no maldecir a los padres: "Quien maldiga a su padre o a su madre morirá

${ }^{42}$ Cfr. Johnson, cit. (n. 4), pp. 17-26.

${ }^{43}$ Cfr. Pritikin, Martin H., Punishment, Prisons, and the Bible: Does "Old Testament Justice" Justify Our Retributive Culture?, en Cardozo Law Review, 28/2 (2006), pp. 716-717.

${ }^{44}$ Cfr. WeIngReEn, Jacob, cit. (n. 3), pp. 123-124. 
sin remedio por haber maldecido a su padre o a su madre: caiga sobre él su sangre" (Lv 20,9), y se castigan con la muerte conductas sexuales que se consideran abominables (Lv 20,10-16) ${ }^{45}$. También la adivinación o la evocación de espíritus es algo abominable (Lv 20,27). Pero, sobre todo, será reo de muerte el que blasfeme contra $\operatorname{Dios}^{46}$ o el que dé muerte a otro hombre (Lv 24,16-17).

En la mayor parte de los casos en que está prevista una condena a muerte, no se especifica el modo en que se ejecutará al reo. En el Código de la Alianza, el más antiguo, no se dice nada sobre esto. A partir del Código Deuteronómico, se va especificando en algunas ocasiones que la muerte será por lapidación. El caso más conocido es cuando se mantienen relaciones sexuales por parte de alguien que ya está ligado a otra persona, sea desposada o casada: "Si una joven virgen está desposada con un hombre, y otro la encuentra en la ciudad y yace con ella, sacaréis a ambos a la puerta de esa ciudad y lapidaréis a ambos hasta que mueran" (Dt 22,23$24)^{47}$. También se ejecutará así a los reos de dar culto a quienes se postran en adoración al sol o la luna, o a otros dioses (Dt 17,3-5).

En la Ley de Santidad se aplica este modo de ejecución a casos relacionados con graves delitos de tipo religioso como es el caso de quien haya evocado a los difuntos o practicado la adivinación ( $\mathrm{Lv}$ 20,27), el de quien ofrezca a Moloc sacrificios humanos (Lv 20,2), y el de quien profiera blasfemias (Lv 24,16.23)

En dos ocasiones se menciona la hoguera: "Si uno toma por esposa a una mujer y a la madre de ésta, comete una perversión. Él y ellas serán quemados en la hoguera para evitar que esa perversión se dé entre vosotros" (Lv 20,14) y "si la hija de un sacerdote se deshonra prostituyéndose, deshonra a su padre. Será quemada en el fuego" $(\operatorname{Lv} 21,9)$. A tenor de lo que se cuenta en el libro de Josué de un caso análogo, parece que la quema en la hoguera es posterior a la muerte por lapidación de los culpables (Jos 7,15-25). El fuego no sería el modo de ejecución, sino que tendría un sentido purificador de la abominación cometida ${ }^{48}$.

También hay un par de textos en que se mencionan "colgados" o "ahorcados" (Nm 25,4-5 y Dt 21,22-23), pero nunca como modos previstos de ejecutar una

${ }^{45}$ Cfr. Burnside, Jonathan, Strange Flesh: Sex, Semiotics and the Construction of Deviancy in Biblical Law, en Journal for the Study of the Old Testament, 30/4 (2006), pp. 387-420; SCHENKER, Adrian, What Connects the Incest Prohibitions with the Other Prohibitions Listed in Leviticus 18 and 20?, en Rendtorff, Rolf y Kugler, Robert (eds.), Book of Leviticus: Composition and Reception (Leiden, Brill Academic Publishers, 2003) pp. 162-185.

${ }^{46}$ En los códigos legales más antiguos (Alianza y Deuteronómico) no se especificaba que la blasfemia contra Dios conllevase la pena de muerte, aunque el episodio de la lapidación de Nabot (1 R 21,1-19) pone de manifiesto que estaba en uso esa costumbre. Cfr. FuAD, Chelcent, The Curious Case of the Blasphemer: Ambiguity as Literary Device in Leviticus 24:10-23, en Horizons in Biblical Theology, 41/1 (2019), p. 54. Sobre las singularidades de este pasaje de la Ley de Santidad, véase Leuchter, Mark, The Ambiguous Details in the Blasphemer Narrative: Sources and Redaction in Leviticus 24:10-23, en Journal of Biblical Literature, 130/3 (2011), pp. 431-450 y VROOM, Jonathan, Recasting mišpa tîm: Legal Innovation in Leviticus 24:10-23, en Journal of Biblical Literature, 131/1 (2012), pp. 27-44.

${ }^{47}$ Cfr. Reeder, Caryn A., Wives and Daughters: Women, Sex, and Violence in Biblical Tradition, en Ex auditu, 28 (2012), pp. 122-141.

${ }^{48}$ Cfr. BAR, Shaul, The punishment of burning in the Hebrew Bible, en Old Testament Essays, 25/1 (2012), pp. 27-39. 
sentencia, sino como ejecuciones extrajudiciales de facto por parte de algún vengador o por quien quiso dar un castigo ejemplar ante la gente.

En cualquier caso, es significativo que el modo ordinario de ejecutar una sentencia de muerte en el derecho bíblico sea la lapidación. Máxime cuando en el mundo mediterráneo y en el próximo oriente eran frecuentes otros modos de ejecución: decapitar, crucificar, empalar, etc. ¿Por qué en la ley bíblica sólo se especifica la lapidación?

Hay un texto que puede dar pistas, aunque no se trata de una norma legal, sino de una instrucción para un momento determinado. Llama la atención lo que se dice en el libro del Éxodo cuando se prohíbe a la gente acercarse al monte humeante donde poco después se va a manifestar el Señor: "Os guardaréis de subir a la montaña, y hasta de aproximaros a su falda. El que se aproxime a la montaña morirá sin remedio. Pero nadie pondrá la mano sobre el culpable, sino que será lapidado o asaeteado; sea hombre o animal no quedará con vida" (Ex 19,12-13). La concreción de que nadie pondrá su mano sobre el que haya infringido el mandato, sino que será lapidado o asaeteado (dos modos de ejecución "a distancia”, sin golpear directamente al reo), tal vez ayude a comprender el por qué se prefiere la lapidación: puede ser un modo de dar muerte a alguien cuando la justicia lo requiera, pero sin que nadie realice personalmente la ejecución con un contacto directo sino mediante unos instrumentos (piedras, flechas) que realizan su acción mediando una cierta distancia entre los verdugos y el reo. De este modo, no quedarán sus manos literalmente "manchadas de sangre", como señal de respeto a la sangre que lleva consigo el carácter sagrado de la vida.

\section{Pena de "extirpación"}

Ya que estamos hablando de la pena capital en los textos de la Torah, hagamos un breve inciso para hablar de un concepto que en algunos textos puede parecer como sinónimo de "condenar a muerte" o "ejecutar" pero que designa, muy probablemente, una "muerte virtual”, es decir, un apartamiento de actividades relacionadas con el culto o la vida social. Me refiero al término "extirpar" (karat, literalmente: "cortar" [de en medio de su pueblo] $)^{49}$.

Puede clarificar el misterioso sentido de esa expresión lo que se indica en un texto sacerdotal tardío de Números acerca de quien deliberadamente no celebró la Pascua: "Pero si uno que estaba puro y no se encontraba en camino se abstuvo de celebrar la Pascua, ése será extirpado de su pueblo, porque no ofreció la ofrenda del Señor en su momento; ese hombre será responsable de su pecado" $(\mathrm{Nm} 9,13)$. ¿Se está diciendo que "será ejecutado"? No lo parece. Más bien se tratará de una situación ritual que le impide volver a participar con normalidad en el culto. En esa línea invita a considerar el sentido de "será extirpado" otro texto del mismo tiempo

\footnotetext{
${ }^{49}$ Richard C. Steiner señala, con razón, que "cortar a alguien de su pueblo" es el antónimo de "añadirlo o unirlo al pueblo": STEINER, Richard C., Disembodied Souls: the Nefesh in Israel and Kindred Spirits in the Ancient Near East, with an appendix on the Katumuwa Inscription (Atlanta, SBL Press, 2015), p. 126. Un estudio sobre un caso particular de káret puede encontrarse en Tsevat, Matitiahu, Interpretation of 1 Sam 2:27-36. The Narrative of Kareth, en Hebrew Union College Annual, 32 (1961), pp. 191-216.
} 
y del mismo libro: "el hombre que quede impuro y no se purifique, ese hombre será extirpado de la asamblea, pues ha contaminado el Santuario del Señor. El agua lustral no lo ha rociado, queda impuro" ( $\mathrm{Nm}$ 19,20). Parece claro que se trata de penas rituales y no físicas.

Una revisión pormenorizada de todos $\operatorname{los} \operatorname{textos}^{50}$, en la que no nos detendremos ahora, pone de manifiesto que la pena de "extirpación" (káret) no conduce a una situación irreversible, sino que está dirigida a la prevención de algunos delitos, $\mathrm{y}$, eventualmente, cuando se han cometido y se ha incurrido en ella, a provocar una reflexión que lleve a la corrección y la rehabilitación.

\section{Castigos corporales}

Ya dijimos que la mayor parte de las normas jurídicas de la Torah no llevan anejas penas asociadas a su incumplimiento, salvo en algunas cuestiones de singular relevancia, en las que se señala la pena de muerte, o la de "extirpación" o apartamiento de la comunidad. Pero, en contadas ocasiones, se especifican castigos corporales de distinta consideración.

Hay un caso, un tanto singular, en donde parecería establecerse una pena de mutilación. Forma parte de una colección miscelánea de leyes en el libro del Deuteronomio, y en la traducción más corriente se puede leer: "Si un hombre está peleándose con otro, y se acerca la mujer de uno de ellos para librar a su marido del que le golpea, y alargando la mano (yad) lo agarra por sus partes, le cortarás (weqassotah) la mano (kaf): no se apiadarán tus ojos" (Dt 25,11-12).

Salta a la vista que es desproporcionado el que, por intervenir en ayuda de su marido, se le aplique a la mujer una pena tan severa. Se trata, ciertamente, de un texto de difícil interpretación. Llama, por ejemplo, la atención el cambio de término hebreo referido a la "mano". El primero que se utiliza, yad, es la palabra más habitual para designarla. En cambio, el segundo, kaf, designa de ordinario la palma de la mano, pero también puede ser una superficie curva, de ahí que en algunos textos sea un eufemismo para designar los genitales ${ }^{51}$. Esto hace que algunos autores piensen que se trata de algún modo de aplicación de la ley del talión a la mujer por los daños proferidos, o la injuria realizada, al hombre que luchaba con su marido ${ }^{52}$. Otros, también en aplicación de la ley del talión, hablan de pagar la injuria cometida con otra injuria equivalente, sugiriendo traducir weqassotah como "le rasurarás" y considerando el uso de kaf como un eufemismo ${ }^{53}$.

${ }^{50}$ Los textos a los que me refiero son Ex 12,19; 30,33; 30,38; 31,14; Lv 7,20-27; Lv 17,4; 17,$9 ; 18,29 ; 19,8 ; 22,3 ; 23,29 ; \mathrm{Nm} 9,13 ; 19,20$.

${ }^{51}$ Cfr. ElliotT, John Hall, Deuteronomy - Shameful Encroachment on Shameful Parts: Deuteronomy 25:11-12 and Biblical Euphemism, en EsLER, Philip Francis (ed.), Ancient Israel: the Old Testament in its social context (Minneapolis, Augsburg, 2006), pp. 161-176; ElliotT, John Hall, Deuteronomy 25:11-12 LXX: no Tweaking the Twins: More on a Biblical Euphemism and its Translation, en STRECKER, Christian (ed.), Kontexte der Schrift: Wolfgang Stegemann zum 60. Geburtstag (Stuttgart, W. Kohlhammer, 2005), pp. 323-342.

${ }^{52}$ Algún autor ha sugerido que también en este caso se podría tratar de una aplicación de la ley del talión. Cfr. Contez, Marc, The law on violent intervention: Deuteronomy 25:11-12 revisited, en Journal for the Study of the Old Testament, 30/4 (2006), pp. 431-447.

${ }^{53}$ Cfr. WALSH, Jerome T., 'You shall cut off her...palm' ?: a reexamination of Deuteronomy 
Al margen de esta posible pero no probable excepción, en todos los demás casos en que se habla de mutilación es en la aplicación de la ley del talión para quien haya producido deliberadamente una lesión a otra persona. Esta escasez de alusiones a penas de mutilación es llamativa en comparación con las leyes babilónicas en las que era una pena de uso frecuente $e^{54}$.

En cualquier caso, la pena corporal por excelencia es la de azotes, que siempre ha de ser proporcionada al delito, y en la que hay normas concretas para que el verdugo no se exceda: "Si el culpable merece azotes, el juez mandará que se eche en tierra y le darán azotes en su presencia, en número proporcionado a su maldad. Podrá mandar darle hasta cuarenta azotes; no podrá añadir ninguno más: si se excediera de esos azotes, tu hermano quedaría envilecido ante tus ojos" (Dt 25,2-3) ${ }^{55}$.

Es digno de hacerse notar que los castigos corporales sólo están previstos, y con las condiciones señaladas, como penas por delitos cometidos, nunca como modo de tortura ni de coacción para obtener confesiones o informaciones ${ }^{56}$.

\section{Multas o compensaciones económicas}

Además de castigos corporales, en algunos comportamientos injustos, se prevé que quien los haya cometido, deba resarcir al perjudicado con algún tipo de bienes materiales. En el Código de la Alianza las penas son muy fuertes: "Cuando uno robe un buey o una oveja y lo mata o lo vende, pagará cinco reses de ganado mayor por el buey y cuatro reses de ganado menor por la oveja” (Ex 21,37). Es decir, cuando el mismo animal robado no puede ser devuelto, porque murió o fue vendido, además de restituir uno como él, ha de incrementarlo en un 400 o $300 \%$ dependiendo de si era una res de ganado mayor o menor. En cambio, si la propiedad no ha sido destruida, sino que se mantiene indemne bastará con devolverla añadiendo otra análoga: "si lo robado, sea un buey, un asno o una oveja, se encuentra todavía vivo en su poder, pagará el doble” (Ex 22,3). Es decir, la sanción es del $100 \%$ en este caso.

Este tipo "multas" o sanciones económicas son más frecuentes en la Ley de Santidad, el código legal más tardío y desarrollado de los que se integran en la Torah, pero son llamativamente más leves.

Se mencionan, de una parte, daños causados por inadvertencia a cosas relacionadas con el culto: "Si alguien ofende y peca por inadvertencia, en perjuicio de las cosas santas del Señor, ofrecerá como sacrificio por el delito un macho cabrio del rebaño, sin defecto, según la tasación en siclos de plata, en siclos del santuario, para sacrificio por el delito. Tendrá que restituir el daño que hizo en las cosas santas y añadirá un quinto de su valor. Lo dará al sacerdote, que hará la expiación por él con el macho cabrio del sacrificio por el delito, y le quedará perdo-

25:11-12, en Journal of Semitic Studies, 49/1 (2004), pp. 47-58.

${ }^{54}$ Estaba previsto, por ejemplo, cortar la mano derecha del cirujano si uno de sus pacientes moría durante una cirugía. Cfr. BARTON, George, Archaeology and the Bible (Philadelphia, American Sunday School Union, 1937), p. 400.

${ }^{55}$ Cfr. Kent, Charles Foster, The Humanitarian Element in the Old Testament Legislation, en The Biblical World, 18/4 (1901), pp. 270-283.

${ }^{56}$ Williams, Gary R., cit. (n. 5), p. 47. 
nado" (Lv 5,15-16). El suplemento de "un quinto" de su valor que se añade a la restitución del daño causado no es en especie sino en su equivalente monetario. La sanción, en este caso, es de un $20 \%$ de lo dañado. Un caso análogo es el de Lv 22,14: "si por inadvertencia alguien come una cosa santa, restituirá al sacerdote la cosa santa y añadirá un quinto”.

También se mencionan daños inferidos a otras personas por parte de alguien que está arrepentido y se presenta ante el sacerdote para reconocer y expiar su falta: "Quien haya pecado así y se haya hecho culpable, restituirá el despojo que hizo, o lo que robó, o el depósito que se le entregó, o aquello que habia encontrado, o cualquier cosa sobre la que juró con mentira. Lo restituirá integramente y añadirá un quinto de su valor, entregándolo a su propietario el dia del sacrificio por el delito" (Lv 5,23-24).

Como se puede apreciar, en la Ley de Santidad la "multa" es de un quinto del valor de lo sustraído. En cambio, en el Código de la Alianza, el precio a añadir era de varias veces que el que tenía lo robado o dañado. La diferencia fundamental es que, en la Ley de Santidad, el código más tardío y avanzado, se toma en consideración el reconocimiento del daño causado y el arrepentimiento ${ }^{57}$.

\section{V. ¿QUÉ IDEA DEL HOMBRE IMPLICAN ESAS NORMAS?}

Antes de terminar esta rápida mirada que acabamos de realizar sobre lo que se puede señalar acerca de la teoría del delito que está implícita en las leyes bíblicas, vale la pena que nos detengamos a hacer unas breves reflexiones acerca de lo que refleja ese derecho penal.

\section{Prioridad de los valores religiosos y la vida humana}

Un rasgo característico de la ley bíblica, que se hace más notorio por el contraste con otras fuentes legales del próximo oriente, es la prioridad que otorga a los valores religiosos y la vida humana, por encima de las consideraciones económicas y políticas que subyacen en las leyes de los pueblos vecinos ${ }^{58}$. Especialmente, en lo que respecta a los elementos de derecho penal que se pueden encontrar en su sistema jurídico, llama la atención que los delitos que son castigados con más severidad son los delitos religiosos y aquellos que atentan contra la vida y la estructura familiar, mientras que en las leyes mesopotámicas los daños a los bienes económicos, como tierras, ganados y personas, en cuanto mano de obra, son los más penados ${ }^{59}$.

${ }^{57}$ La comparación de esas normas más tardías con lo establecido en otros códigos antiguos del Próximo Oriente resalta la suavidad con la que el ladrón es tratado en la Ley de Santidad. De este modo, suavizando las penas a quien reconoce el daño causado, se facilita la confesión espontánea, favoreciendo la posibilidad de que las víctimas puedan recuperar lo perdido en casos en que el descubrimiento del ladrón no hubiera sido posible por falta de evidencias. Cfr. Milgrom, Jacob, cit. (n. 35), pp. 328-330.

${ }^{58}$ Cfr. Greenberg, Moshe, Some Postulates of Biblical Criminal Law, en Haran, Menahem (ed.), Yehezkel Kaufmann Jubilee Volume (Jerusalem, Magnes Press, 1960), p. 19.

${ }^{59}$ Cfr. Código de Hammurabi 6-11, 21-25. 
Por ejemplo, en el Código de Hammurabi el allanamiento, saqueo, incendio y robo ${ }^{60}$ está penado con la muerte, pero en la ley bíblica ningún delito contra la propiedad ordinaria lleva consigo la pena capital. En cambio, mientras que los sistemas legales vecinos permitían una compensación monetaria para eludir la muerte por parte de quien había cometido un homicidio, no sucede así, como hemos visto, en la Biblia.

En contraste con otros sistemas legales que priorizan la lealtad al poder establecido, las leyes bíblicas ponen en primer lugar la fidelidad a un Dios que no está al servicio de los gobernantes, que incluso les pone límites a su autoridad ${ }^{61}$, y que prioriza el bien de las personas singulares. Como Eckart Otto hace notar: "Por primera vez en la historia cultural del antiguo oriente los valores éticos están desgajados de la lealtad al gobernante"62. En hebreo "dar culto" es lo mismo que "servir" (abad), de ahí que ningún señor temporal pueda sustituir al Señor (YHWH), Dios de Israel, y esto tiene severas consecuencias no sólo religiosas sino también sociales, lo que explica la relevancia penal dada al primero de todos los mandamientos.

\section{Responsabilidad individual}

Otro rasgo singular de la ley bíblica es la responsabilidad individual por los daños que alguien puede infligir a otra persona. Aunque ahora a nosotros nos pueda parecer obvio, en una sociedad donde la venganza tenía carta de ciudadanía, no es superfluo que se valore una precisión relevante, como es aquella en la que establece que la retribución es personal, y la pena debida sólo debe recaer en quien cometió el delito, no en cualquiera de su clan: "Los padres no han de ser castigados con la muerte por culpa de los hijos, ni los hijos por culpa de los padres: cada uno morirá sólo por su propio pecado"(Dt 24,16). Por contraste, en el Código de Hammurabi si se derrumbaba una casa por estar construida defectuosamente y mataba al hijo del dueño, el hijo del constructor que la edificó debía ser ejecutado ${ }^{63}$.

\section{El sentido de la pena}

Ya hemos hablado de que en la legislación bíblica hay previstos varios tipos de penas: muerte, daños corporales, sobre todo azotes, y también compensaciones o penas económicas. También hemos hecho notar que nunca se contempla el caso de encerrar a alguien en la cárcel durante un cierto tiempo como pena por un delito cometido ${ }^{64}$.

A la vista de las penas establecidas y de la motivación que se hace de ellas, no parece que la corrección del delincuente fuera un objetivo prioritario, ni siquiera relevante, en el sistema penal.

\footnotetext{
${ }^{60}$ Código de Hammurabi, 21-25.

${ }^{61}$ Cfr. Pérez Gondar, Diego, Culto, autoridad y tradición. La comunidad judia de Elefantina y la religiosidad vinculada a su templo, en Scripta Theologica, 50/1 (2018), pp. 23-52.

${ }^{62}$ Otто, Eckart, Law and Ethics, en Johnston, Sarah Iles (ed.), Religions of the Ancient World. A Guide (Cambridge MA, The Belknap Press of Harvard University Press, 2004) p. 88.

${ }^{63}$ Código de Hammurabi, 230.

${ }^{64}$ Cfr. Williams, Gary R., cit. (n. 5), pp. 49-50.
} 
El objetivo principal era la reparación del daño producido por el delito ${ }^{65}$. Esto es más obvio en los casos de daños a los bienes materiales (campos, propiedades, ganado, etc.), pero también es lo que estaría detrás de la venganza de sangre en el caso de homicidios dolosos. La norma básica es conocida como "ley del talión” y tiene formulaciones muy parecidas en los tres grandes códigos (Ex 21,23-25 en el Código de la Alianza; Dt 19,21 en el Deuteronómico y Lv 24,17-21 en la Ley de Santidad ${ }^{66}$. Es digno de señalarse que, posteriormente, en la la literatura rabínica se considera que no se han de causar daños físicos, sino que se ha de exigir una reparación económica proporcionada al daño infligido ${ }^{67}$.

También hay algunos detalles relevantes en la legislación bíblica acerca del sentido de la pena. Uno de ellos es que es necesario arrancar al mal ${ }^{68}$ : hay delitos especialmente graves que suponen un oprobio para la tierra y que no pueden ser tolerados, sino que han de ser erradicados con firmeza ${ }^{69}$. A este respecto es ilustrativo lo señalado en un texto del que hablamos al principio sobre alguien que da "culto a dioses extraños y se postra ante ellos, ante el sol, la luna o cualquiera de los seres de los cielos" (Dt 17,3). Una vez realizada una cuidadosa indagación, tras escuchar a varios testigos, a la hora de ejecutar la sentencia, se dice que "la mano de los testigos será la primera en actuar contra él para darle muerte, y después la mano de todo el pueblo. Asi arrancarás el mal de en medio de ti" (Dt 17,7). Hay varios casos más en los que se aduce exactamente el mismo objetivo (Dt 19,1113; 21,18-21 y 24,7): "arrancar el mal de en medio de ti”, es decir, del pueblo. Por eso son los testigos y el pueblo mismo quienes han de ejecutar la sentencia.

Una cuestión singular de la legislación bíblica es la consideración de que hay delitos, por ejemplo el homicidio, de tal magnitud que requieren realizar una reparación del desorden causado, incluso aunque no se pueda saber quién fue el culpable, y no se pueda imponer a nadie la pena que restaure ese crimen ${ }^{70}$. A este respecto es relevante la siguiente prescripción del Código Deuteronómico: "Si en la tierra que el Señor, tu Dios, te da en posesión se encontrara una persona muerta, tendida en el campo, sin que se sepa quién la mató, saldrán tus ancianos y tus jueces y medirán la distancia desde la víctima a las ciudades de alrededor, y determinarán cuál sea la ciudad más próxima al cadáver. Después, los ancianos de esa ciudad tomarán una ternera con la que aún no se haya trabajado ni haya tirado del yugo. Harán bajar la ternera al lecho de un rio de agua perenne, que no haya sido labrado ni sembrado, $y$ alli, en el torrente, la desnucarán. Entonces se acercarán los sacerdotes hijos de Levi: a ellos eligió el Señor, tu Dios, para su servicio, para bendecir en su nombre y para que según su palabra se dirima cualquier pleito y cualquier lesión. Luego, todos los

${ }^{65}$ Cfr. Williams, Gary R., cit. (n. 5), pp. 43-44 y 54.

${ }^{66}$ Cfr. Frymer-Kensky, Tikva, cit. (n. 15), pp. 232-233.

${ }^{67}$ Cfr. CHINITZ, Jakob, Eye for an Eye - An Old Canard, en Jewish Quarterly Review, 23/2 (1995), pp. 79-85.

${ }^{68}$ Acerca del sentido de esta expresión, véase L’Hour, Jean, cit. (n. 3), p. 4.

${ }^{69}$ Cfr. Williams, Gary R., cit. (n. 5), p. 54.

${ }^{70}$ Cfr. L'Hour, Jean, cit. (n. 3), pp. 19-21. La solemne ceremonia del día de la expiación, con el rito del chivo expiatorio (cf. Lv 5,34) se enmarca en esta necesidad de expiar por todos los delitos que se hayan cometido. 
ancianos de esa ciudad más próxima al cadáver, se lavarán las manos en el río sobre la ternera desnucada, y declararán solamente: 'Nuestras manos no han derramado esta sangre y nuestros ojos no han visto nada: ;Oh Señor! Perdona a tu pueblo Israel, al que liberaste, y no imputes la sangre inocente a tu pueblo Israel'. Y les será expiada esta sangre" (Dt 21,1-8) ${ }^{71}$. Se trata, muy probablemente, de un rito de purificación para desterrar el mal, eliminando de la comunidad las consecuencias de un derramamiento de sangre ${ }^{72}$.

\section{Valor pedagógico de la ley}

Hay un texto en el Deuteronomio que produce cierta desazón, por lo aparentemente desproporcionado, al lector actual: "Si un hombre tuviera un hijo rebelde e incorregible, que no escuch a la voz de su padre ni de su madre y, aunque le corrigen, no les hace caso, su padre y su madre lo tomarán y lo conducirán a los ancianos de su ciudad, a la puerta del lugar. Entonces declararán ante ellos: 'Este hijo nuestro rebelde e incorregible no escucha nuestra voz; es un comilón y bebedor'. Entonces, todos los hombres de la ciudad lo lapidarán hasta que muera" (Dt 21,18-21a). Ahora bien, lo que sigue posiblemente puede explicar el sentido de esa prescripción: "todo Israel lo oirá y temerá" (Dt 21,21b). Ese inciso, en una norma que parece castigar desproporcionadamente un delito "menor", un chico rebelde, comilón y bebedor, que hace sufrir a sus padres, puede llevar a plantearse la cuestión de si esas penas ejecutaban siempre, o tenían más bien un valor disuasorio. Esto es, ¿estamos ante una legislación prevista para ser aplicada? $\mathrm{O}$ ¿se trata de una normativa pedagógica para instruir acerca de lo que debe hacerse y no hacerse, o de qué está bien y qué está mal, o qué se considera especialmente grave?

También otras normas legales producen análoga perplejidad, como aquella del Levítico que dice que "si uno cohabita con la mujer de un tío suyo, ha descubierto la desnudez de su tío. Cargarán con su iniquidad. Morirán sin hijos. Si uno toma por esposa a la mujer de su hermano comete una ignominia. Ha descubierto la desnudez de su hermano. Quedarán sin hijos"(Lv 20,20-21). En su escueta formulación no queda claro si es una condena o una maldición, ya que ¿cómo se ejecuta el morirán sin hijos? Podría entenderse que los matarán por ese delito, pero en el segundo caso, paralelo al anterior, se dice que quedarán (¡no morirán!) sin hijos. Esto no parece que implique ni una condena a muerte, ni mucho menos la muerte de los hijos que tuvieran en ese momento, ni tampoco una esterilización que lo impidiera en el futuro. Pienso que es un reflejo del carácter disuasivo más que ejecutivo que tiene esta y no pocas más de estas normas legales.

${ }^{71}$ El carácter oscuro del texto y la singularidad de esta normativa posiblemente está en el origen de diversas variaciones textuales en la versión de los Setenta. Cfr. Dion, Paul-Eugène, The Greek Version of Deut 21:1-9 and its Variants: A Record of Early Exegesis, en PIETERSMA, Albert y Cox, Claude (eds.), De Septuaginta: studies in honour ofJohn William Wevers on his 65th birthday (Mississauga Ontario, Benben Publications, 1984), pp. 151-160. También ha dejado ecos en los midrašim: Walfish, Ruth, Joseph and the eglah arufah, en Jewish Bible Quarterly, 40/1 (2012), pp. 25-28.

${ }^{72}$ Cfr. WRIGHT, David P., Deuteronomy 21:1-9 as a rite of elimination, en The Catholic Biblical Quarterly, 49/3 (1987), pp. 387-403. 
Incluso, en algunos pasajes, el tono en que están redactados pone de manifiesto este carácter pedagógico de la ley: "Actúa de acuerdo con la sentencia que te indiquen en aquel lugar que haya elegido el Señor, y esmérate en hacer cuanto te señalen. Obra de acuerdo con la norma que te enseñen y con la sentencia que te dicten. No te desvies del camino que te indiquen ni a derecha ni a izquierda. El hombre que obre con altivez, sin escuchar al sacerdote que esté alli para el servicio del Señor, tu Dios, ni al juez, ese hombre morirá. Asi arrancarás el mal de Israel. Todo el pueblo, al oirlo, temerá y en adelante no obrará con altivez" (Dt 17,10-13).

En síntesis, se podría decir que en la legislación bíblica la pena no tiene un sentido de venganza, sino que está orientada a restablecer sin excesos la justicia dañada, a la vez que posee un efecto disuasorio.

En esta línea no deja de ser significativo que el nombre con el que la tradición hebrea ha designado la Ley haya sido el de Torah. Se trata de un sustantivo de la raíz yarah que significa "lanzar, marcar el camino" y de ahí "enseñar, instruir", que es la misma que aparece en el sustantivo moreh, "maestro". Literalmente, torah significa "instrucción, enseñanza"73. No se la contempla como una mera normativa consecuencia de una voluntad arbitraria de Dios ni mucho menos como un consenso humano para organizar razonablemente la convivencia. Esta concepción tiene de fondo la idea de que el Dios de Israel es un Dios bueno y todopoderoso, que ha creado el cielo y la tierra, las plantas, los animales y los hombres, y que ha hecho todo con una grandiosa sabiduría organizado con unas leyes -las de la naturaleza- que gobiernan el buen funcionamiento de todo lo creado. En ese gran contexto, la Torah es como el manual de instrucciones del fabricante, las indicaciones acerca de cómo funcionará bien la relación entre los hombres, ya sea entre sí en la vida social y nacional, ya sea en su relación con la naturaleza.

\section{BiBLIOGRAFÍA}

BAR, Shaul, The punishment of burning in the Hebrew Bible, en Old Testament Essays, 25/1 (2012), pp. 27-39.

Berlin, Adele, Sex and the Single Girl in Deuteronomy 22, en Fox, Nili Sacher, Glatt-Gilad, David A. y Williams, Michael J. (eds.), Mishneh Todah: Studies in Deuteronomy and its cultural environment in honor of Jeffrey H. Tigay (Winona Lake Ind., Eisenbrauns, 2009) pp. 95-112.

BOZHEKU, Ersi, Tracing the criminal justice: an inquiry into the roots of the modern penal principles, en Curentul Juridic, 18/2 (2015), pp. 94-106.

Burnside, Jonathan, God, Justice, and Society (Oxford, Oxford University Press, 2011).

- Strange Flesh: Sex, Semiotics and the Construction of Deviancy in Biblical Law, en Journal for the Study of the Old Testament, 30/4 (2006), pp. 387-420. https://doi. org/10.1177/0309089206067465

Chinitz, Jakob, Eye for an Eye - An Old Canard, en Jewish Quarterly Review, 23/2 (1995), pp. 79-85.

${ }^{73}$ Cfr. Diamond, Arthur Sigismund, Primitive Law, Past and Present (London, Methuen \& Co. Ltd., 1971), p. 124. 
Cocco, Francesco, The Torah as a Place of Refuge. Biblical Criminal Law and the Book of Numbers (Tübingen, Mohr Siebeck, 2016).

CorTez, Marc, The law on violent intervention: Deuteronomy 25:11-12 revisited, en Journal for the Study of the Old Testament, 30/4 (2006), pp. 431-447. https://doi. org/10.1177/0309089206067466

Daube, David, Direct and Indirect Causation in Biblical Law, en Vetus Testamentum, 11 (1961), pp. 246-269. https://doi.org/10.2307/1516223

Diamond, Arthur Sigismund, Primitive Law, Past and Present (London, Methuen \& Co. Ltd., 1971).

Dion, Paul-Eugène, The Greek Version of Deut 21:1-9 and its Variants: A Record of Early Exegesis, en Pietersma, Albert y Cox, Claude (eds.), De Septuaginta: studies in honour of John William Wevers on his 65th birthday (Mississauga Ontario, Benben Publications, 1984), pp. 151-160.

Elliotr, John Hall, Deuteronomy - Shameful Encroachment on Shameful Parts: Deuteronomy 25:11-12 and Biblical Euphemism, en EsLer, Philip Francis (ed.), Ancient Israel: the Old Testament in its social context (Minneapolis, Augsburg, 2006), pp. 161-176.

—Deuteronomy 25:11-12 LXX: no Tweaking the Twins: More on a Biblical Euphemism and its Translation, en STRECKER, Christian (ed.), Kontexte der Schrift: Wolfgang Stegemann zum 60. Geburtstag (Stuttgart, W. Kohlhammer, 2005), pp. 323-342.

Fensham, F. Charles, Exodus 21:18-19 in the light of Hittite law 10, en Vetus Testamentum, 10/3 (1960), pp. 333-335.

Flatto, David C., Constructing Justice: The Selective Use of Scripture in Formulating Early Jewish Accounts of the Courts, en Harvard Theological Review, 111/4 (2018), pp. 488-515. https://doi.org/10.1017/S001781601800024X

Frymer-Kensky, Tikva, Tit for tat: The Principle of Equal Retribution in Near Eastern and Biblical Law, en Biblical Archeologist, 43 (1980), pp. 230-234. https://www. doi.org/10.2307/3209797

FuAD, Chelcent, The Curious Case of the Blasphemer: Ambiguity as Literary Device in Leviticus 24:10-23, en Horizons in Biblical Theology, 41/1 (2019), pp. 51-70. https://doi.org/10.1163/18712207-12341385

Greenberg, Moshe, Some Postulates of Biblical Criminal Law, en Haran, Menahem (ed.), Yehezkel Kaufmann Jubilee Volume (Jerusalem, Magnes Press, 1960), pp. 5-28.

HADAD, Eliezer, 'Unintentionally' (Numbers 35:11) and 'Unwittingly' (Deuteronomy 19:4): Two Aspects of the Cities of Refuge, en AJS Review, 41/1 (2017), pp. 155-173. https://doi.org/10.1017/S0364009417000071

JACKSON, Bernard, On the Values of Biblical Law and their Contemporary Application, en Political Theology 14/5 (2013), pp. 602-618. https://doi.org/10.1179/1462 317X13Z.00000000038

- Wisdom \& Laws: A Study of the Mishpatim of Exodus 21:1-22:16 (Oxford, Oxford University Press, 2006).

- The Problem of Exod. xxi.22-25 (Ius Talionis), en Vetus Testamentum, 23 (1973), pp. 273-304. https://www.doi.org/10.2307/1517325

Johnson, Scott L., The Bible and the Death Penalty: Implications for Criminal Justice Education, en Journal of Criminal Justice Education, 11/1 (2000), pp. 15-33. https://doi.org/10.1080/10511250000084731 
JONKER, Louis C., Achaemenid Understanding of Law and Justice in Darius I's Tomb Inscriptions: Are There Any Connections with Hebrew Bible Pentateuchal Conceptions?, en Scandinavian Journal of the Old Testament, 33/1 (2019), pp. 24-41. https:// doi.org/10.1080/09018328.2019.1599625

KAŠNÝ, Jiří, Criminal Law in the Hebrew Bible (en checo), en Studia Theologica, 18/2 (2016), pp. 1-21. https://doi.org/10.5507/sth.2016.014

Kent, Charles Foster, The Humanitarian Element in the Old Testament Legislation, en The Biblical World, 18/4 (1901), pp. 270-283.

Leuchter, Mark, The Ambiguous Details in the Blasphemer Narrative: Sources and Redaction in Leviticus 24:10-23, en Journal of Biblical Literature, 130/3 (2011), pp. 431-450. https://www.doi.org/10.2307/41304212

L'Hour, Jean, Une législation criminelle dans le Deutéronome, en Biblica, 44 (1963), pp. 1-28.

Makujina, John, The Semantics of in Exodus 21:22: Reassessing the Variables that Determine Meaning, en Bulletin for Biblical Research, 23/3 (2013), pp. 305-321.

Mattison, Kevin, Contrasting Conceptions of Asylum in Deuteronomy 19 and Numbers 35, en Vetus Testamentum, 68/2 (2018), pp. 232-251. https://doi. org/10.1163/15685330-12341316

Milbank, John, Theology and the Idea of University, en Scripta Theologica, 50/2 (2018), pp. 253-273. https://doi.org/10.15581/006.50.2.253-273

Milgrom, Jacob, Leviticus 1-16. The Anchor Bible (New York, Doubleday, 1991).

NAEH, Shlomo y SHEmESH, Aharon, Deuteronomy 19:15-19 in the Damascus Document and Early Midrash, en Dead Sea Discoveries, 20 (2013), pp. 179-199.

Nardoni, Enrique, Rise Up, O Judge: A Study of Justice in the Biblical World (Peabody Massachusetts, Hendrickson Publishers, 2004).

Nelson, Richard D., Deuteronomy: A Commentary (Louisville, Westminster John Knox, 2002).

Ninan, Christophe, From Priestly Torah to Pentateuch: A Study in the Composition of the Book of Leviticus (Tübingen, Mohr Siebeck, 2007).

Osumi, Yuichi, Die kompositionsgeschichte des Bundesbuches Exodus 20,22b-23,33 (Freiburg-Göttingen, Vandenhoeck \& Ruprecht, 1991).

Отто, Eckart, Law and Ethics, en Johnston, Sarah Iles (ed.), Religions of the Ancient World. A Guide (Cambridge MA, The Belknap Press of Harvard University Press, 2004), pp. 84-97.

PEARCE, Sarah, Speaking with the voice of God: the high court according to Greek Deuteronomy 17:8-13, en Hempel, Charlotte y Lieu, Judith M. (eds.), Biblical traditions in transmission: essays in honour of Michael A. Knibb (Leiden -Boston, Brill, 2006), pp. 237-247.

PÉREZ Gondar, Diego, Culto, autoridad y tradición. La comunidad judía de Elefantina y la religiosidad vinculada a su templo, en Scripta Theologica, 50/1 (2018), pp. 2352.https://doi.org/10.15581/006.50.1.23-52

PIKov, Gennady, Criminal Law in the Bible (en ruso), en Schole: Ancient Philosophy and the Classical Tradition, 4/1 (2010), pp. 101-136.

Pritikin, Martin H., Punishment, Prisons, and the Bible: Does "Old Testament Justice" Justify Our Retributive Culture?, en Cardozo Law Review, 28/2 (2006), pp. 715-778.

ReEder, Caryn A., Wives and Daughters: Women, Sex, and Violence in Biblical Tradition, en Ex auditu, 28 (2012), pp. 122-141. 
SCHONEVeld, Jacobus, Le sang du cambrioleur: Exode 22:1,2, en BöHL, Franz Marius Theodor y BeEK, Martinus Adrianus (eds.) Symbolae Biblicae et Mesopotamicae: Francisco Mario Theodoro de Liagre Böhl dedicatae, (Leiden, Brill, 1973), pp. 335-340.

SCHENKer, Adrian, What Connects the Incest Prohibitions with the Other Prohibitions Listed in Leviticus 18 and 20?, en ReNDTORFF, Rolf y Kugler, Robert (eds.), Book of Leviticus: Composition and Reception (Leiden, Brill Academic Publishers, 2003), pp. 162-185.

SChwienhorst-SchönBerger, Ludger, Das Bundesbuch (Ex 20,22-23,33). Studien zu seiner Entstehung und Theologie (Berlin, De Gruyter, 1990).

SeEBASS, Horst, Zum Sklavenrecht in Ex 21,28-32 und der Diskrepanz zwischen Ersatzrecht und Todesrecht, en Zeitschrift für altorientalische und biblische Rechtsgeschichte, 5 (1999), pp. 179-185.

STACKERT, Jeffrey, Why does Deuteronomy legislate cities of refuge?: asylum in the covenant collection (Exodus 21:12-14) and Deuteronomy (19:1-13), en Journal of Biblical Literature, 125/1 (2006), pp. 23-49. https://www.doi.org/10.2307/27638345

STEINER, Richard C., Disembodied Souls: the Nefesh in Israel and Kindred Spirits in the Ancient Near East, with an appendix on the Katumuwa Inscription (Atlanta, SBL Press, 2015).

STULMAn, Louis, Encroachment in Deuteronomy. An analysis of the Social World of the D Code, en Journal of Biblical Literature, 109/4 (1990), pp. 613-632. https://www. doi.org/10.2307/3267366

TigaY, Jeffrey H., Deuteronomy: The Traditional Hebrew Text with the New JPS Translation (Philadelphia, Jewish Publication Society, 1996).

TSEVAT, Matitiahu, Interpretation of 1 Sam 2:27-36. The Narrative of Kareth, en Hebrew Union College Annual, 32 (1961), pp. 191-216.

VARO, Francisco, L'arrière-plan sociologique du champ sémantique de l'étranger dans le Pentateuque, en Revue des sciences philosophiques et theologiques, 102/3 (2018), pp. 385-414. https://doi.org/10.3917/rspt.1023.0385

VROOM, Jonathan, Recasting mišpa tîm: Legal Innovation in Leviticus 24:10-23, en Journal of Biblical Literature, 131/1 (2012), pp. 27-44.

WaGner, Angela B., Considerations on the Politico-Juridical Proceedings of Genesis 34, en Journal for the Study of the Old Testament, 38/2 (2013), pp. 145-161. https:// doi.org/10.1177/0309089213511757

WaLFISH, Ruth, Joseph and the eglah arufah, en Jewish Bible Quarterly, 40/1 (2012), pp. 25-28.

WALSH, Jerome T., 'You shall cut off her...palm??: a reexamination of Deuteronomy 25:11-12, en Journal of Semitic Studies, 49/1 (2004), pp. 47-58. https://doi. org/10.1093/jss/49.1.47

Weingreen, Jacob, Concepts in Ancient Biblical Civil and Criminal Law, en The Irish Jurist, 24 (1989), pp. 113-140.

WeStBROOK, Raymond y Wells, Bruce, Everyday Law in Biblical Israel (Louisville Kentucky, Westminster John Knox Press, 2009).

Whitekettle, Richard, Life's Labors Lost: Priestly Death and Returning Home From a City of Refuge in Ancient Israel, en Harvard Theological Review, 111/3 (2018), pp. 333-356. https://doi.org/10.1017/S0017816018000147 
Williams, Gary R., The Purpose of Penology in the Mosaic Law and Today, en Bibliotheca Sacra, 133 (1976), pp. 42-55.

Wright, David P., Deuteronomy 21:1-9 as a rite of elimination, en The Catholic Biblical Quarterly, 49/3 (1987), pp. 387-403. 